FERnANDo Muniz Shecaira

\title{
PARTICIPAÇÃO NOS JULGAMENTOS DE CASOS REPETITIVOS
}

\author{
Dissertação de Mestrado \\ Orientadora: Professora Dra. Susana Henriques da Costa
}

UNIVERSIDADE DE SÃo PAULO

FACULDADE DE DIREITO

SÃo PAULO

2019 

FERNANdo Muniz Shecaira

\section{PARTICIPAÇÃO NOS JULGAMENTO DE CASOS REPETITIVOS}

Dissertação de Mestrado apresentado à Banca Examinadora do Programa de Pós-Graduação em Direito da Faculdade de Direito da Universidade de São Paulo, como parcial exigência para obtenção do título de Mestre em Direito, na área de concentração de Direito Processual, sub-área de Direito Processual Civil, sob a orientação da Profa. Dra. Susana Henriques da Costa.

UNIVERSIDADE DE SÃo PAULO

FACULDADE DE DiREITO

SÃo PAULO

2019 
Shecaira, Fernando Muniz

Participação nos Julgamentos de Casos Repetitivos ; Fernando Muniz Shecaira ; orientadora Susana Henriques da Costa -- São Paulo, 2019. 166

Dissertação (Mestrado - Programa de Pós-Graduação em Direito Processual) - Faculdade de Direito, Universidade de São Paulo, 2019.

1. Litigiosidade Repetitiva. 2. Democracia Participativa. 3. Pesquisa Empirica. 4. Sociologia do Processo. I. Costa, Susana Henriques da, orient. II. Título. 
SHECAIRA, Fernando Muniz: Participação nos Julgamentos de Casos Repetitivos.

Dissertação (Mestrado em Direito) - Faculdade de Direito, Universidade de São Paulo. São Paulo, 166 p., 2019.

Aprovado em:

Banca Examinadora

Professor(a) Dr(a).

Instituição:

Julgamento:

Professor(a) Dr(a).

Instituição:

Julgamento:

Professor(a) Dr(a).

Instituição:

Julgamento: 

A todas as vítimas da fome e a todos os famélicos da terra.

Essa dissertação, sozinha, não contribui para uma terra sem amos: mas pode trazer luz em momentos dificeis 



\section{AgRAdeCimentos}

Agradeço, primeiramente, à minha orientadora Susana Henriques da Costa, cujos ensinamentos de um processo civil justo e equânime serão marca indelével de meus futuros trabalhos.

Sem menor importância, agradeço aos meus companheiros do Grupo de Pesquisa de Acesso à Justiça e Litigiosidade Repetitiva na pessoa de um dos maiores presentes da minha passagem pela Pós-Graduação na Faculdade de Direito, meu colega João Francisco Eberhardt, que me inspirou de luz nos momentos mais sombrios.

Agradeço, também, aos meus companheiros advogados, diretores, estagiários e, sobretudo, funcionários, do Departamento Jurídico XI de Agosto, na pessoa da Maria Cecília de Araújo Asperti, a Ciça, cujos brilhantismo e lucidez me fazem sonhar em crescer profissionalmente todos os dias.

Alguns professores marcaram a minha trajetória acadêmica nestes anos todos, importando para nota os sempre presentes Carlos Alberto de Salles e Daniela Monteiro Gabbay, que em banca de qualificação me alavancaram na pesquisa empírica; os inspiradores Paulo Eduardo Alves da Silva e Pedro Heitor Barros Geraldo, que na apresentação de meu trabalho no Congresso da ABraSD me aprofundaram no tema da participação;

Não poderia deixar de frisar a importância das amizades em momentos difíceis da redação desse estudo: a Andrea Miranda e a Camila Oliveira, sem as quais não teria tido forças para completar essa jornada; a Gabriela Cunha, Aline Martins, Gabriel Mantelli e Mariana Del Chiaro, sem os quais não teria tido paz de espírito para enfrentar meus maiores desafios; a Ana Beatriz Garcia e a Patricia Monteiro Rocha, sem as quais não teria tido as risadas nos momentos de descanso. 
A meus primos que, embora sejam minha família, não deixaria de tê-los ao meu lado por nada nesse mundo: Carolina Shecaira, Laura Moore, Tânia Shecaira, Nina Ferrari, Giorgio Ferrari, sem vocês eu não seria metade de quem sou hoje.

Ao restante da minha família, nas pessoas das minhas avós Aparecida Maria Baldassa Muniz e Ismênia Isaac, cujas raízes penetraram fundo no chão e possibilitaram o nascimento de muitos frutos, um dos quais apresento hoje.

E, acima de tudo, a meus pais, Cibele Cristina Baldassa Muniz e Sérgio Salomão Shecaira: dedico este trabalho, pelo apoio emocional, psicológico, afetivo, financeiro e espiritual, além de auxílio na correção deste trabalho. Sem vocês nada disso teria sido possível. Espero um dia poder retribuir cada gota de suor, cada carinho e cada torcida. 


\section{RESUMO}

SHECAIRA, Fernando Muniz: Participação nos Julgamentos de Casos Repetitivos. Dissertação (Mestrado em Direito) - Faculdade de Direito, Universidade de São Paulo. São Paulo, 166 p., 2019.

O objeto deste estudo é a percepção do Tribunal de Justiça do Estado de São Paulo acerca da participação dos litigantes nos julgamentos dos incidentes de resolução de demandas repetitivas. A hipótese de pesquisa a ser testada é a de que o Judiciário ainda responde à necessidade de participação a partir de um dimensionamento restrito do conceito de contraditório. O trabalho se estrutura em três partes. Na Parte Primeira, verificou-se haver casos concretos de participação nos Três Poderes que formam o Estado Brasileiro. A análise dos casos concretos nos três poderes colheu da realidade material da sociedade brasileira elementos que induzissem a necessidade de estudos teóricos acerca do assunto explorado. Na Parte Segunda, procedeu-se à revisão bibliográfica. Na Parte Terceira, lançou-se mão de pesquisa empírica, adotando a técnica de entrevistas pouco estruturadas, com abordagem qualitativa, utilizando-se de tópicos-guia para se buscar conhecer, na realidade concreta, se os desembargadores do Tribunal de Justiça de São Paulo concebem um contraditório largamente dimensionado. Houve saturação das entrevistas, limitando-as ao número de doze. A totalidade dos desembargadores entrevistados afirmou não haver problema na conjectura de inexistir participação nos julgamentos de processos repetitivos. Apesar de um entusiasmo na participação dos litigantes nos incidentes de resolução de demandas repetitivas, não haveria nulidades em inexistir participação: o processo tramitaria normalmente e dele resultaria um julgamento sem a efetiva participação dos litigantes, confirmando a hipótese.

Palavras-chave: processo civil, litigiosidade repetitiva, participação, democracia, sociologia jurídica, sociologia do processo. 


\begin{abstract}
SHECAIRA, Fernando Muniz: Participation in Repetitive Case Judgments. Dissertation (Master in Law) - Faculty of Law, University of São Paulo. São Paulo, 166 p., 2019.

The purpose of this study is the perception of the Court of Justice of the State of São Paulo regarding the participation of the litigants in the trials of the incident of resolution of repetitive demands. The research hypothesis is that the Judiciary still responds to the need for participation from a restricted dimension of the audi alteram partem constitutional norm. The work is structured in three parts. In the First Part, there were concrete cases of participation in the Three Branches that make up the Brazilian State. The analysis of the concrete cases in the Three Branches gathered from the material reality of Brazilian society induced the need for theoretical studies about the subject explored. In Part Two, the bibliographic review was carried out. In the Third Part, empirical research was used, adopting the technique of unstructured interviews, with a qualitative approach, using guiding topics to seek to know, in the concrete reality, if the judges of the Court of Justice of São Paulo conceive of a principle of audi alteram partem in a broad perspective. There was saturation of the interviews, limiting them to the number of twelve. The totality of the interviewed judges stated that there was no problem in the conjecture that there was no participation in the trials of repetitive processes. Despite enthusiasm in the participation of the litigants in the incidents of resolution of repetitive demands, there would be no nullities in the absence of participation: the process would normally proceed and would result in a judgment without the effective participation of the litigants, confirming the hypothesis.
\end{abstract}

Keywords: civil procedure, repetitive litigation, participation, democracy, sociolegal studies, sociology of the process. 


\section{SUMÁRIO}

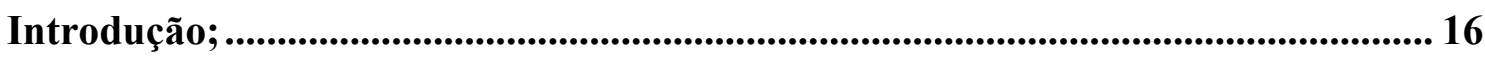

Parte Primeira - O QUAdro de estrutura Real da PARTICIPAÇão POPUlar nos

PODERES DA REPÚBLICA; ..................................................................................... 20

1. A participação popular nos Poderes da República; ................................................... 20

1.1. O marco da experiência de Participação Popular na Nova República: O Orçamento

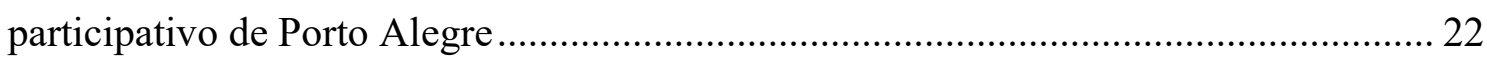

1.2. A Participação Popular no Poder Executivo: As agências reguladoras .................... 27

1.3. A Participação Popular no Poder Legislativo: As audiências públicas para

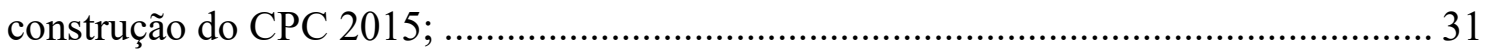

1.4. A Participação Popular no Poder Judiciário: O caso ciclovias; e ............................. 39

1.5. Considerações Parciais da Parte Primeira........................................................................ 46

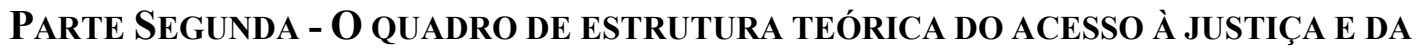

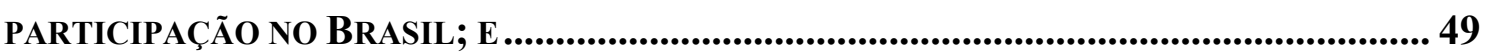

2. A cidadania com a participação da sociedade; .................................................... 49

2.1. A evolução do Estado sob a ótica da participação;.............................................. 50

2.2. Estado Democrático de Direito - O resgate da participação direta; e ...................... 57

2.3. Democracia participativa, semi-representativa ou semidireta no Brasil................. 61

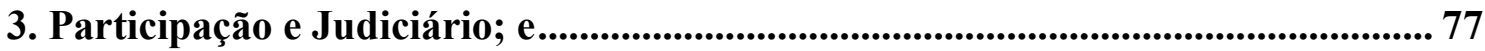

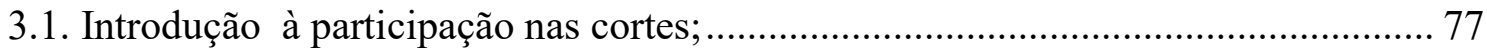

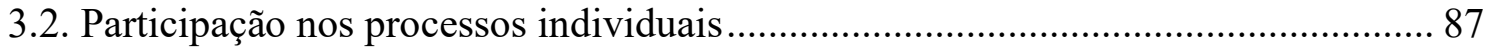

3.3. Participação nos julgamentos de processos coletivos; ............................................ 95

3.4. Participação nos julgamentos de processos repetitivos; e .................................... 107

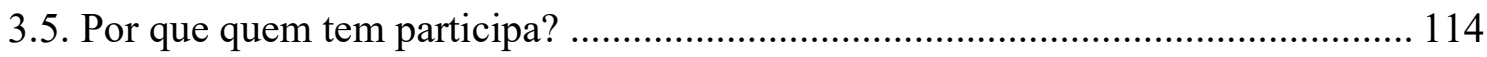

Parte Terceira - A pesquisa empírica: Como se dá a ParticipaÇão nos

Julgamentos de CASOS RePETITIVOS. ........................................................... 122

4. Participação nos Julgamentos de Casos Repetitivos. ............................................... 122 
4.1. Primeiras notas acerca do objeto estudado;

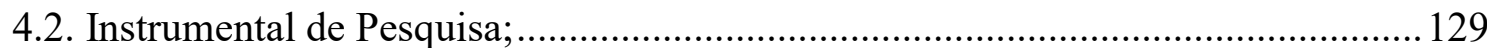

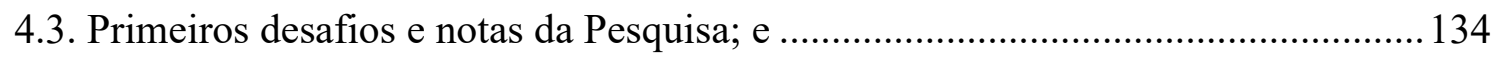

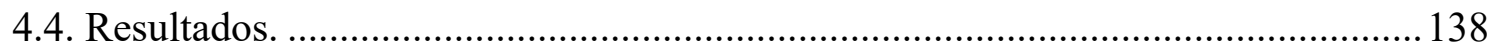

4.4.1. Entusiasmo em relação à participação nos julgamentos de processos repetitivos;

4.4.2. Qualidade, quantidade e efetividade de participação nos julgamentos de processos

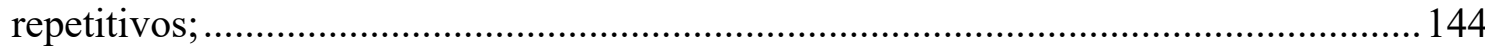

4.4.3. Caráter jurídico do incidente de resolução de demandas repetitivas; e................ 151

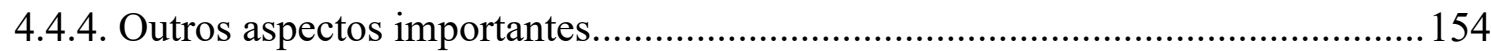

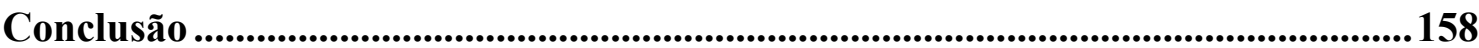

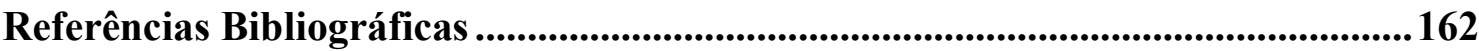

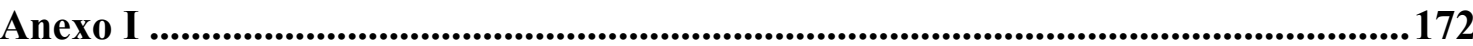

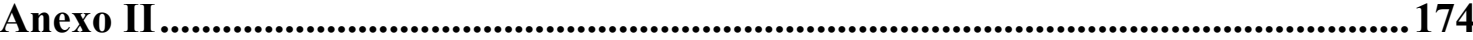

Anexo III ......................................................................................................................... 176 


\section{LisTRA DE QUADROS E FigurAS}

Figura 1. A comunicação como nível de observação privilegiado da pesquisa

130

Figura 2. Permeabilidade das Seções do Tribunal acerca da Participação dos Litigantes;

Figura 3. Litigantes necessários para processamento do IRDR 



\section{INTRODUÇÃO;}

Quem nos dias de hoje sabe os nomes dos Ministros de Estado brasileiros? Talvez nem nos corredores de uma Universidade seja possível encontrar alguém que acerte todos os seus nomes - ou sequer quantos compõem o alto escalão do Executivo. Contudo, a probabilidade de acharmos pessoas que saibam nomes de alguns Ministros do Supremo Tribunal Federal, ou a quantidade de magistrados que lá se encontram, ou, talvez, algum dos Ministros que lá estiveram, parece ser bem maior.

O Judiciário brasileiro saiu de um mero "orador da lei” para membro importante no epicentro político nacional - seja por causa de julgamentos de partidos políticos, seja por causa de julgamento de escândalos de corrupção, seja pelo controle judicial de políticas públicas.

Esse foco no Judiciário torna a discussão das crises jurídicas e políticas algo muito mais palatável e próximo da sociedade, algo que nessa magnitude seja talvez inédito na História do Brasil.

Mas será que a sociedade pode participar dos Poderes da República? Pode ela interferir na criação de políticas públicas? No processo legislativo? Nos processos coletivos? Nos processos judiciais de formação de precedentes?

Ainda, estão os Poderes da República dispostos a abrir suas portas à participação popular? Estão eles capacitados a deixar a sociedade civil participar dos seus respectivos processos - de administrar, legislar e julgar?

Nesse último processo, de julgar, surgiu uma nova tecnologia dentro da reforma do sistema processual que tenta manejar a litigiosidade repetitiva dentro do Poder Judiciário. Mas será que além de dar uma resposta à repetitividade de demandas, dá esse instituto uma resposta à sociedade de maneira participativa?

O objeto deste trabalho parte desses questionamentos, preferindo focar no Tribunal de Justiça de São Paulo por uma questão de recorte metodológico, 
viabilidade temporal e da proximidade com o local da realização desse estudo, bem como a possibilidade de aprofundamento do tema proposto. Consequentemente, busca-se estudar como o Tribunal de Justiça do Estado de São Paulo concebe a participação dos litigantes nos julgamentos dos incidentes de resolução de demandas repetitivas. $\mathrm{O}$ realce será na análise da participação uma vez que instaurado o incidente, por maior viabilidade da pesquisa.

Além disso, a realidade tem demonstrado que a participação da sociedade em julgamentos de casos repetitivos ainda é reduzida, mas há uma tendência a se permitir a abertura dos outros Poderes à participação popular por força da Constituição Federal de 1988 - sendo que essa seria aplicável a todos os três Poderes. Além disso, há um afastamento de parte da sociedade do centro de decisão dos julgamentos de casos repetitivos, mormente por critérios socioeconômicos. Essas questões serão trazidas à baila deste estudo para que se entenda como se dá essa participação e por quem ela se dá.

A hipótese de pesquisa a ser testada é a de que o Judiciário ainda responde à necessidade de participação a partir de um dimensionamento restrito do conceito de contraditório. Apesar da discussão oriunda das décadas de 70 e 80 de que o processo individual não é o único que deve existir no ordenamento para solucionar as crises jurídicas, devendo haver, em paralelo, os processos coletivos e, mormente agora, os processos envolvendo demandas repetitivas, o Judiciário não estaria nem capacitado nem disposto a promover a participação de todos os diversos tipos de litigantes em concordância com o ideal democrático traçado como pressuposto neste trabalho.

A metodologia adotada por esse estudo engloba primordialmente o método hipotético-dedutivo, onde se pretende testar a hipótese por meio da empiria.

Num primeiro momento, será avaliada a realidade material da participação no Judiciário brasileiro. Nessa primeira parte, serão analisados os diversos aspectos sociológicos que envolvem o tema, não se focando tanto nas teorias e na doutrina, mas mais em dados empíricos que deem uma ideia geral do "estado da arte" do tema estudado, numa interlocução entre sociologia e processo a que recentemente se dá o nome de "sociologia do processo". 
Adiante será traçado o marco teórico que dimensionará o que se entende, neste estudo, por participação nos Poderes da República, tendo a Participação e Judiciário um capítulo próprio. Além disso, busca-se analisar se e por que "quem tem" participa no processo, à revelia de "quem não tem". Almeja-se traçar as bases teóricas para que se possa testar empiricamente a hipótese proposta.

A parte terceira e última deste trabalho foca na aplicação do quadro teórico apreendido da realidade material a casos concretos e, como o parâmetro é o hipotético-dedutivo, testa se a teoria se concretiza na prática ou se permanece nos corredores das bibliotecas.

O instrumental dessa parte será multi-metódos, focando-se no estudo de congregação de casos e, também, em entrevistas semiestruturadas com os magistrados relatores dos julgamentos de casos repetitivos, ambos com uma abordagem majoritariamente qualitativa, não se excluindo, contudo, alguma quantificação sem possibilidade de generalização por inexistência de estudo estatístico. 


\section{CONCLUSÃo}

O presente trabalho pretendeu perquirir sobre a percepção dos desembargadores do Tribunal de Justiça de São Paulo acerca da participação dos litigantes nos julgamentos de casos repetitivos. A hipótese era a de que os desembargadores dimensionam o contraditório de forma restrita.

$\mathrm{Na}$ Parte Primeira, verificou-se haver casos concretos de participação nos Três Poderes que formam o Estado Brasileiro: comentou-se sobre o marco da participação democrática no Brasil, o caso do Orçamento Participativo de Porto Alegre; também, foram trazidos dados sobre a participação em agências reguladoras, no bojo do Poder Executivo a nível Federal; seguindo, estudou-se a participação na elaboração do anteprojeto do Código de Processo Civil brasileiro de 2015, quando analisado o Poder Legislativo Federal; finalmente, a nível do Poder Judiciário, estudouse um caso paradigmático envolvendo a municipalidade, Ministério Público e Judiciário paulistas.

A análise dos casos concretos nos três poderes colheu da realidade material da sociedade brasileira elementos que induzissem a necessidade de estudos teóricos acerca do assunto explorado.

Para tanto, na Parte Segunda, lançou-se mão de uma revisão bibliográfica que questionava (i) o conceito democracia participativa, (ii) se a democracia participativa estava configurada nos ditames da Constituição Federal de 1988, (iii) como ocorre a democracia participativa no âmago do processo judicial, sobretudo (iv) como acontece a participação nos processos repetitivos e, finalmente, (v) por que quem tem participa, em detrimento de quem não tem.

As conclusões a que se chegou durante o exercício da dialética literária foram as seguintes: 
i. a democracia participativa engloba a democracia indireta, entendida pelo direito oriundo das revoluções liberais para poder votar e ser votado, e a democracia direta, em que há entrada da população no sistema estatal por vias alternativas às da primeira, vias essas que devem ser facilitadas e não dependentes de dinheiro ou poder organizacional ou institucional.

ii. a democracia participativa está encravada na Constituição Federal de 1988 como norma obrigatória a todos os Três Poderes, ou seja, norma cogente ao Poder Executivo, Legislativo e, também, ao Poder Judiciário.

iii. a participação ocorre por meio do exercício do contraditório, nas demandas individuais; pelo exercício da representatividade adequada, nos processos coletivos, e (iv) pela participação como amicus curiae, terceiros interessados e audiências públicas, nos julgamentos de casos repetitivos.

iv. os litigantes habituais ("quem tem"), possuem diversas vantagens em relação aos litigantes ocasionais ("quem não tem"), e essas vantagens podem levar a um abuso no imo dos processos repetitivos, razão pela qual o Judiciário deve agir para evitar esse déficit de participação por parte da sociedade, sob pena de violar a Constituição Federal.

Consequentemente, e em uma primeira relação com a hipótese deste trabalho, verificou-se que era necessário um dimensionamento mais alargado e abrangente do contraditório, para que se cumprisse com a democracia participativa no ventre do Poder Judiciário, caso contrário, parte da sociedade - os litigantes ocasionais poderiam acabar afastados dos centros decisórios de poder. 
Retornando à materialidade, agora para falsear a hipótese de que, apesar de haver previsão de alargamento do contraditório, os desembargadores percebem a participação de forma relativamente restrita.

Para tanto, na Parte Terceira, lançou-se mão de pesquisa empírica, adotando a técnica de entrevistas pouco estruturadas para se buscar conhecer, na realidade concreta, se os desembargadores concebem um contraditório largamente dimensionado.

Verificou-se que, apesar de haver um certo avanço em relação à participação, com a possibilidade de que quaisquer pessoas adentrem os processos de julgamento de casos repetitivos, a tônica de uma das Seções do Tribunal de Justiça de São Paulo é mais avessa à participação do que a outra.

Os desembargadores entrevistados da Seção de Direito Privado, mostraram-se entusiasmados em relação à participação das partes, inclusive afirmando que houve diversas vezes envio de ofícios a entidades representativas de litigantes ocasionais, exatamente para possibilitar que todos participassem do processo de julgamento dos casos repetitivos.

Contudo, especificamente na Seção de Direito Público, algumas vezes foi relatado que a Turma Especial tende e conceber o processo decisório do incidente de resolução de demandas repetitivas como mero julgamento de um direito objetivo, sem a necessidade de que quaisquer partes estejam presentes.

Se havia dúvidas acerca da confirmação da hipótese por parte dos desembargadores entrevistados da Seção de Direito Privado, não é o mesmo que se pode vislumbrar dos desembargadores entrevistados da Seção de Direito Público que, muito embora haja vozes dissonantes dentro dessa Seção, essas mesmas vozes afirmam ser minoritárias.

Contudo, a confirmação da hipótese se dá de maneira mais inequívoca quando se analisam as respostas dos desembargadores em relação à eventualidade de que nenhuma entidade representativa dos interesses de litigantes 
ocasionais compareça ao processo de julgamento de casos repetitivos, ou seja, quando há uma violação do contraditório que legitima democraticamente esse tipo de processo.

A totalidade dos desembargadores entrevistados afirmou que não haveria algo a se fazer na conjectura proposta. Ou seja, que o processo tramitaria normalmente e que dele resultaria um julgamento.

Essa ausência de participação no processo individual (por ferir o direito à defesa) ou no processo coletivo (por não haver representatividade adequada) é motivo de nulidade. Porém, a mesma previsão de nulidade não acontece no fundo do processo repetitivo.

Como visto, contudo, tal nulidade deveria ocorrer, sob pena de se deslegitimar o processo repetitivo por déficit democrático e por violação de um contraditório estendido, situação essa que tende a ser desvantajosa ao litigante ocasional.

Por todo o exposto, é possível afirmar que, de acordo com os métodos empíricos adotados, foi possível confirmar a hipótese de que os desembargadores do Tribunal de Justiça de São Paulo dimensionam o contraditório de maneira restrita, concebendo a participação dos litigantes - ocasionais - como mero facilitador da atividade judicatória, não sendo condição sine qua non para não eivar o processo repetitivo de déficit democrático e de legitimidade. 


\section{REFERÊNCIAS BIBLIOGRÁFICAS}

ABDAL, Alexandre; OLIVEIRA, Maria Carolina Vasconcelos; GHEZZI, Daniela Ribas; SANTOS JR., Jaime: Métodos de pesquisa em Ciências Sociais - Bloco Qualitativo. São Paulo: Cebrap, 2016

AGUILLAR, Fernando Herren: As Tibiezas do empirismo radical. In AGUILLAR, Fernando Herren: Metodologia da Ciência do Direito. São Paulo: Max Limonad, 1999.

: Metodologia da Ciência do Direito. São Paulo: Max Limonad, 1999.

ALMEIDA, Frederico de: Intelectuais e Reforma do Judiciário: os especialistas em direito processual e as reformas da justiça no Brasil. Revista Brasileira de Ciência Política, maio- agosto, n. 17, Brasília, 2015.

ARAÚJO, Edmir Netto de: Curso de Direito Administrativo, $7^{\text {a }}$ ed. São Paulo: Saraiva, 2015. P. 202.

ARAÚJO, Rodrigo Mendes de: A representação adequada nas ações coletivas. Salvador: JusPodium, 2013.

ASPERTI, Maria Cecília de Araújo: Acesso à Justiça e Técnicas de Julgamento de Casos Repetitivos. Tese (Doutorado em Direito), 414 p. Faculdade de Direito da Universidade de São Paulo. São Paulo, 2018.

BARROSO, Luís Roberto: Curso de Direito Constitucional Contemporâneo: os conceitos fundamentais e a construção do novo modelo. São Paulo: Saraiva, 2009.

2009.

: Interpretação e aplicação da Constituição, $7^{a}$ ed. São Paulo: Saraiva,

: O direito constitucional e a efetividade de suas normas, $7^{\mathrm{a}}$ ed. Rio de Janeiro: Renovar, 2003.

BAUER, Martin W. e GASKELL, George (editores): Pesquisa qualitativa com texto, imagem e som - um manual prático. Tradução de Pedrinho A. Guareschi, $3^{\text {a }}$ ed. Petrópolis: Vozes, 2002.

BECKER, Flavia Gil Nusenbaum: Incidente de resolução de demandas repetitivas: um estudo à luz do princípio da igualdade. Dissertação (Mestrado em Direito), Faculdade de Direito, Universidade de São Paulo. São Paulo, 2017.

BEDAQUE, José Roberto dos Santos; CINTRA, Lia Carolina Batista; EDI, Elie Pierre (coords.): Garantismo Processual: Garantias constitucionais aplicadas ao processo. Brasília: Gazeta Jurídica, 2016. 
BOBBIO, Norberto. A Era dos Direitos, 11 a ed. Rio de Janeiro: Campus, 1992.

: O futuro da democracia, $6^{\text {a }}$ ed. Rio de Janeiro, Paz e Terra, 1997.

BONAVIDES, Paulo: Do Estado Liberal ao Estado Social, 9ª ed. São Paulo: Malheiros, 2009.

: Jurisdição constitucional e legitimidade (algumas observações sobre o Brasil). Estudos Avançados 18 (51), 2004.

: Teoria Constitucional da Democracia Participativa - Por um Direito Constitucional de Luta e Resistência, por uma Nova Hermenêutica, por uma repolitização da legitimidade, $3^{\text {a }}$ ed. São Paulo: Malheiros, 2008.

BRYMAN, Alan: Social Research Methods, 4th Edition. Oxford: Oxford University, 2012.

BUENO, Cássio Scarpinella: As class actionsnorte-americanas e as ações coletivas brasileiras: pontos para uma reflexão conjunta. In Revista de Processo, n. 82, ano 21, abr.jun./1996.

CABRAL, Antonio de Passo: A escolha da causa-piloto nos incidentes de resolução de processos repetitivos. In DIDIER JR, Fredie \& CUNHA, Leonardo Carneiro da: Julgamento de casos repetitivos. Coleção Grandes temas do Novo CPC. Vol. 10. Salvador: Juspodium, 2017.

CALDO, Diego Santiago Y: Controle da Representatividade Adequada nas Ações Coletivas: um estudo comparativo dos sistemas brasileiro e norte-americano. Dissertação (Mestrado em Direito), Faculdade de Direito, Universidade de São Paulo, 279 p. São Paulo: 2018.

CAMPOS, Poti Silveira \& SILVEIRA, Núbia: Orçamento participativo de Porto Alegre: 25 anos. Porto Alegre: Editora da Cidade, 2015.

CAPPELLETTI, Mauro: Formações Sociais e interesses coletivos diante da justiça civil. Tradução de Nelson Renato Palaia Ribeiro de Campos. In Revista de Processo, São Paulo, 2, Jan/Mar 1977.

: Acesso à justiça como programa de reforma e como método de pensamento, Processo, ideologia e sociedade, v. 1, Porto Alegre: Sergio Antônio Fabris Editor, 2008

CAPPELLETTI, Mauro e GARTH, Bryant: Acesso à justiça. Porto Alegre: Sergio Antônio Fabris Editor, 1988

CARDOSO, Luciana Zaffalon Leme: A vanguarda paulista na consolidação de uma sociedade formalmente democrática e socialmente fascista: o imbricamento das disputas da política convencional com as disputas corporativas do Sistema de Justiça. 2017, 321 
p.,Tese (Doutorado em Administração Pública e Governo), Escola de Administração de Empresas de São Paulo, Fundação Getúlio Vargas, São Paulo, 2017.

CARNELUTTI, Franceso: Instituições do Processo Civil. Tradução de Adrián Sotero de Witt Batista. V.1. São Paulo: Classic Book, 2000.

CARVALHO, Sabrina Nasser de: Processos Coletivos e Políticas Públicas. São Paulo: Contracorrente, 2016. P. 30.

CASTELLS, Manuel: A sociedade em rede. São Paulo, Paz \& Terra, 2009.

CHIOVENDA, Giuseppe: Instituições de direito processual civil. V. 2. Tradução de Paolo Capitanio. Campinas: Bookseller, 1998.

COSTA, Susana Henriques da: A representação adequada e litisconsórcio - o Projeto de Lei n. 5139/2009. In GOZZOLI, Maria Clara (coord): Em defesa de um novo sistema de processos coletivos: estudos em homenagem a Ada Pellegrini Grinover. São Paulo: Saraiva, 2010.

: O controle Judicial da Representatividade Adequada. In SALLES, Carlos Alberto de (Coord.): As grandes transformações do processo civil brasileiro: homenagem ao Professor Kazuo Watanabe. São Paulo: Quartier Latin, 2009.

COSTA, Susana Henriques da; MIRANDA, Andrea Pimentel de: La participación de terceros em el juicio de incidente de resolución de demandas repetetivas: um análisis del tribunal de justicia de São Paulo. In CASTRO, Marco Fandiño (diretor): La gestión judicial - De los nuevos tribunales civiles. Santiago do Chile: 2018.

CUÉLLAR, Leila. As agências reguladoras e seu poder normativo. São Paulo: Dialética, 2001.

CUNHA, Alexandre dos Santos \& SILVA, Paulo Eduardo Alves da (coords.): Pesquisa empírica em Direito. Rio de Janeiro: IPEA, 2013.

DIDDIER JR, Fredie \& ZANETI JR, Hermes: Curso de direito processual civil, $8^{\mathrm{a}}$ ed. Salvador: JusPodium, 2013.

DIDIER JR, Fredie \& CUNHA, Leonardo Carneiro da (coords.): Julgamento de Casos Repetitivos. Salvador: Juspodium, 2016.

DIDIER JR., Fredie: O controle jurisdicional da legitimação coletiva e as ações coletivas passivas (o art. 82 do CDC). In MAZZEI, Rodrigo \& NOLASCO, Rita Dias (coords.): Processo civil coletivo. São Paulo: Quartier Latin, 2005.

DINAMARCO, Cândido Rangel: Instituições de Direito Processual Civil. 9a. ed. V. I. São Paulo: Malheiros, 2017. 
: Litisconsórcio, $3^{\text {a }}$ ed. São Paulo: Malheiros, 1994.

DROMI, José Roberto: Constituicion, Gobierno y Control. Argentina: Ediciones Ciudad Argentina, 1983.

DUARTE, David. Procedimentalização, participação e fundamentação: para uma concretização do princípio da imparcialidade administrativa como parâmetro decisório. Coimbra: Almedina, 1996.

EBERHARDT, João Francisco: Filtros ao acesso individual à justiça: estudo sobre o incidente de resolução de demandas repetitivas. Tese (Doutorado em Direito). Faculdade de Direito, Universidade de São Paulo, 200 p. São Paulo, 2018.

ESCRIVÃO FILHO, Antônio e SOUSA JÚNIOR, José Geraldo: Para um debate teóricoconceitual e político sobre os direitos humanos. Belo Horizonte: Dplacido, 2016.

GALANTER, Marc: Acesso à Justiça em um Mundo de Capacidade Social em Expansão. Tradução de João Eberhardt Francisco, Maria Cecília de Araújo Asperti e Susana Henriques da Costa. Revista Brasileira de Sociologia do Direito, Porto Alegre, ABraSD, v. 2, n. 1, p. 37-49, jan./jun., 2015.

: Why the haves come out ahead? Speculations on the limits of legal change, Volume 9:1 Law and Society Review, 1974, Republicação (com correções) In Law and Society. Dartmouth, Aldershot: Cotterrell, 1994.

GARCIA, Margarida: Novos Horizontes Epistemológicos para a Pesquisa Empírica em Direito: "descentrar" o sujeito, "entrevistar" o sistema e dessubstancializar as categorias jurídicas. Revista de Estudos Empíricos em Direito, 2014, vol. 1, n. 1,.b

GARCIA DE ENTERRIA, Eduardo; RAMÓN FERNÁNDEZ, Tomás. Curso de Direito Administrativo, Trad. de José Alberto Froes. São Paulo: Revista dos Tribunais, 2014 .

GIDI, Antônio: A Class Action como instrumento de tutela coletiva dos direitos: as ações coletivas em uma perspectiva comparada. São Paulo: RT, 2007.

GOMES, Adriano Camargo: A crise do processo e o julgamento de recursos especiais repetitivos. In BEDAQUE, José Roberto dos Santos; CINTRA, Lia Carolina Batista; EDI, Elie Pierre (coords.): Garantismo Processual: Garantias constitucionais aplicadas ao processo. Brasília: Gazeta Jurídica, 2016.

GOZZOLI, Maria Clara (coord): Em defesa de um novo sistema de processos coletivos: estudos em homenagem a Ada Pellegrini Grinover. São Paulo: Saraiva, 2010

GRECO, Leonardo. "Garantias fundamentais do processo: o processo justo". Novos estudos jurídicos, v. 7, n. 14, 2008.

GRINOVER, Ada Pellegrini et al.: Código brasileiro de defesa do consumidor comentado pelos autores do anteprojeto, 8 a ed. Rio de Janeiro: Forense, 2004. 
: Da class action for damages à ação de classe brasileira: os requisitos da admissibilidade. Revista Forense, ano 96, v. 352.

: Direito Processual Coletivo. In GRINOVER, Ada Pellegrini, MENDES, Aluísio Gonçalves de Castro, WATANABE, Kazuo: Direito Procesusal Coletivo e o Anteprojeto do Código Brasileiro de Processos Coletivos. São Paulo: RT, 2007.

GRINOVER, Ada Pellegrini, MENDES, Aluísio Gonçalves de Castro, WATANABE, Kazuo: Direito Procesusal Coletivo e o Anteprojeto do Código Brasileiro de Processos Coletivos. São Paulo: RT, 2007.

GUIMARÃES, Amanda de Araújo: Ações coletivas como meio de molecularização de demandas. Monografia (Bacharelado em Direito), Faculdade de Direito, Universidade de São Paulo. 2012.

HABERMAS: A constelação pós-nacional, Ensaios Políticos. São Paulo: Littera Mundi, 2001.

HOBSBAWM, Eric. Era dos Extremos: o breve século XX (1914-1991). São Paulo: Companhia das Letras, 1994.

JACOB, Herbert: Debtors in Court: The Consumption of Government Services. Chicago: Rand McNally, 1969.

LEONEL, Ricardo de Barros: Manual do Processo Coletivo, $2^{\mathrm{a}}$ ed. rev. atual. e ampliada. São Paulo: RT, 2011.

LIEBMAN, Enrico Tulio: Manuale di Diritto Processuale Civilie - Principii, $5^{\text {a }}$ ed. Milão: Griuffrè, 1992.

LIMA, Márcia: O uso da entrevista na pesquisa empírica. In ABDAL, Alexandre; OLIVEIRA, Maria Carolina Vasconcelos; GHEZZI, Daniela Ribas; SANTOS JR., Jaime: Métodos de pesquisa em Ciências Sociais - Bloco Qualitativo. São Paulo: Cebrap, 2016.

LIMA, Martonio Mont'Alverne Barreto \& ALBUQUERQUE, Paulo Antonio Menezes (Coords.): Democracia, direito e política: estudos internacionais em homenagem a Friedrich Müller. Florianopólis: Conselho Editorial, 2006.

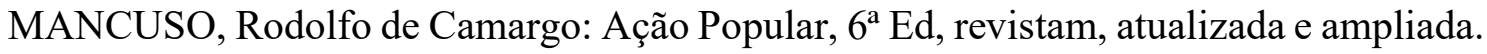
São Paulo: RT, 2008.

MARINONI, Luís Guilherme; ARENHART, Sérgio Cruz: Manual do Processo de Conhecimento, $5^{\mathrm{a}}$ ed., revista, atualizada e ampliada. São Paulo: RT, 2006.

MARINONI, Luiz Guilherme: Teoria Geral do Processo. 3a ed. São Paulo: RT, 2009. : Incidente de resolução de demandas repetitivas. São Paulo: RT, 2016. 
MATTOS, Paulo Todescan Lessa: Regulação Econômica e Social e Participação Pública no Brasil. In NOBRE, Marcos \& COELHO, Vera Schattan P. (orgs): Participação e Deliberação - Teoria Democrática e Experiências Institucionais no Brasil Contemporâneo. São Paulo, Editora 34, 2004.

MAZZEI, Rodrigo \& NOLASCO, Rita Dias (coords.): Processo civil coletivo. São Paulo: Quartier Latin, 2005.

MENDES, Aluisio Gonçalves de Castro: Incidente de resolução de demandas repetitivas, Sistematização, análise e interpretação do novo instituto processual. Rio de Janeiro: Forense, 2017.

MESQUITA, José Ignácio Botelho de: Coisa julgada no código do consumidor. Rio de Janeiro: Forense, 2004.

MILARÉ, Édis: A Ação Civil Pública após 30 anos. São Paulo: RT, 2015.

MIRANDA, Andréa Pimentel de: Quem tem medo do Processo Coletivo? As disputas e as escolhas políticas no $\mathrm{CPC} / 2015$ para o tratamento da litigiosidade repetitiva no Brasil. 174 p. Dissertação (Mestrado em Direito e Desenvolvimento). Escola de Direito de São Paulo. Fundação Getúlio Vargas. São Paulo, 2019.

MORAIS, José Luiz Bolzan de: Crise do estado e democracia: onde está o povo? In LIMA, Martonio Mont'Alverne Barreto \& ALBUQUERQUE, Paulo Antonio Menezes (Coords.): Democracia, direito e política: estudos internacionais em homenagem a Friedrich Müller. Florianopólis: Conselho Editorial, 2006.

MUNIZ, Cibele Cristina Baldassa: Participação Democrática na Administração Pública: Audiências e Consultas Públicas na Lei 9.784/99. 2018, 261 p. Tese (Doutorado em Direito), Faculdade de Direito, Universidade de São Paulo, São Paulo, 2018.

NAGAREDA, Richard A.: Administering Adequacy in Class Representation. Texas Law Review. Austin, University of Texas, School of Law, v. 82, 2003.

NALINI, José Roberto: Novas Perspectivas no Acesso à Justiça. LEX: Jurisprudencia do Supremo Tribunal Federal, v.19., n.224. São Paulo, 1997.

NEVES, Marcelo: Entre Tênis e Leviatã: uma relação difícil. O estado democrático de direito a partir e além de Luhmann e Habermas. São Paulo: Martins Fontes, 2008.

NOBRE, Marcos \& COELHO, Vera Schattan P. (orgs): Participação e Deliberação Teoria Democrática e Experiências Institucionais no Brasil Contemporâneo. São Paulo, Editora 34, 2004.

NOBRE, Marcos \& RODRIGUEZ, José Rodrigo: "Judicialização da política”: déficits explicativos e bloqueios normativistas. In Revista Novos Estudos Cebrap. N. 91. São Paulo: Nov. 2011. 
NOBRE, Marcos: O que é pesquisa em direito. São Paulo: Quartier Latin, 2005.

: Participação e Deliberação na Teoria Democrática - Uma introdução. In NOBRE, Marcos \& COELHO, Vera Schattan P. (orgs): Participação e Deliberação Teoria Democrática e Experiências Institucionais no Brasil Contemporâneo. São Paulo, Editora 34, 2004.

NOHARA, Irene Patrícia: Direito Administrativo. São Paulo: Atlas, 2011.

OLIVEIRA, Carlos Alberto Álvaro de: O processo civil na perspectiva dos direitos fundamentais. Revista da Faculdade de Direito da UFRGS, Porto Alegre, 2002, V. 22.

PACHUKANIS, Eugeni: “A teoria geral do Direito e o Marxismo" e "Ensaios Escolhidos (1921-1929)”. Tradução de Lucas Simone. São Paulo: Sundermann, 2017.

PAULA, Jônatas Luiz Moreira: História do Direito Processual brasileiro: das origens lusas à Escola Crítica do Processo. Barueri: Manole, 2002.

PÊCHEUX, Michel; HENRY, Paul; HAROCHE, Claudine: A semântica e o corte saussuriano: líungua, linguagem e discurso, Tradução de Roberto Leiser Baronas e Fábio César Montanheiro. Revista Linguasagem, n. 3, out/nov, 2008.

PEREIRA, Rodolfo Viana: Direito constitucional democrático: controle e participações como elementos fundantes e garantidores da constitucionalidade. Rio de Janeiro: Lumen Juris, 2008.

PEREZ, Marcos Augusto: A Administração Pública Democrática: Institutos de Participação Popular na Administração Pública. Belo Horizonte: Fórum, 2009.

PORTO, Antônio Maristrello \& SAMPAIO, Patrícia. (orgs.): Direito e economia em dois mundos: doutrina jurídica e pesquisa empírica. Rio de Janeiro: FGV, 2013

RODRIGUES, Marcelo Abelha: Técnicas individuais de repercussão coletiva $\mathrm{x}$ técnicas coletivas de repercussão individual. Por que estão extinguindo a ação civil pública para a defesa de direitos individuais homogêneos?. In MILARÉ, Édis: A Ação Civil Pública após 30 anos. São Paulo: RT, 2015.

ROQUE, André Vasconcelos: Ações coletivas e procedimentos para a resolução de casos repetitivos: Qual o espaço destinado a cada um? In DIDIER JR, Fredie \& CUNHA, Leonardo Carneiro da (coords.): Julgamento de Casos Repetitivos. Salvador: Juspodium, 2016.

ROUSSEAU, Jean Jacques: O Contrato Social: princípios do direito político, $4^{\mathrm{a}}$ ed. São Paulo: Martins Fontes, 2006.

SALLES, Carlos Alberto de (Coord.): As grandes transformações do processo civil brasileiro: homenagem ao Professor Kazuo Watanabe. São Paulo: Quartier Latin, 2009. 
2011.

: Arbitragem em Contratos Administrativos. Rio de Janeiro: Forense,

SANTOS, Boaventura de Sousa (Coord.): Democratizar a democracia, os caminhos da democracia participativa. Reinventar a emancipação social para novos manifestos. Rio de Janeiro: Civilização Brasileira, 2002.

: A difícil democracia: reinventar as esquerdas. São Paulo: Boitempo, 2016.

: A Gramática do Tempo: para uma nova cultura política. São Paulo:

Cortez, 2006.

: Poderá o direito ser emancipatório? Revista Crítica de Ciências Sociais, v. 65. Coimbra: Centro de Estudos Sociais da Universidade de Coimbra. Maio, 2003.

: Para uma revolução democrática da justiça, $2^{\mathrm{a}}$ ed. São Paulo: Cortez, 2008.

SANTOS, Boaventura de Sousa; AVRITZER, Leonardo: Introdução. In SANTOS, Boaventura de Sousa (Coord.): Democratizar a democracia, os caminhos da democracia participativa. Reinventar a emancipação social para novos manifestos. Rio de Janeiro: Civilização Brasileira, 2002.

SIQUEIRA, Fábio; KARLMEYER-MERTENS, Roberto; FUMANGA, Mario; BENEVENTO, Cláudia: Como elaborar projeto de pesquisa: linguagem e método. Rio de Janeiro: FGV, 2008.

SHECAIRA, Fernando Muniz: Eficácia do controle judicial em políticas públicas: o caso "creche". Revista Científica UMC, v.2, n. 2, 2017.

: Poderes Instrutórios do Juiz no Direito de Família - Uma análise Empírica de sua aplicação. Monografia (Bacharelado em Direito), Faculdade de Direito, Universidade de São Paulo. São Paulo, 2012.

SILVA, Fábio de Sá e: Vetores, desafios e apostas possíveis na pesquisa empírica em direito no brasil, Revista de Estudos Empíricos em Direito, vol. 3, n. 1.

SILVA, José Afonso da. Comentário Contextual à Constituição de 1988. 2a ed. São Paulo: Malheiros, 2006.

2009.

: Curso de Direito Constitucional Positivo, $32^{\mathrm{a}}$ ed. São Paulo: Malheiros, : Democracia Participativa. Cadernos de Soluções Constitucionais 2. São

Paulo: Malheiros, 2006; 
TEMER, Sofia: Incidente de resolução de demandas repetitivas. São Paulo: Juspodium, 2018 .

THEODORO JR., Humberto: Curso de Direito Processual Civil, $6^{\text {a }}$ Ed, v. 1. Rio de Janeiro: Forense.

TOCQUEVILlE, Alexis. A democracia na América - Sentimentos e opiniões: de uma profusão de sentimentos e opiniões que o estado social democrático fez nascer entre os americanos, Livro II, tradução Eduardo Brandão, 2a ed. São Paulo: Martins Fontes, 2014.

TRUBEK, David M.: The handmaiden's revenge: on reading and using the newer sociology of civil procedure. Law and Contemporary Problems, vol. 51, n. 4, 1988.

UGARTE, Pedro Salazar: Que Participação para qual Democracia? In NOBRE, Marcos \& COELHO, Vera Schattan P. (orgs): Participação e Deliberação - Teoria Democrática e Experiências Institucionais no Brasil Contemporâneo. São Paulo, Editora 34, 2004.

ULLEN, Thomas Shahan: Um Prêmio Nobel para a Ciência Jurídica: teoria, trabalho empírico e o método científico no estudo do direito. In PORTO, Antônio Maristrello \& SAMPAIO, Patrícia. (orgs.): Direibto e economia em dois mundos: doutrina jurídica e pesquisa empírica. Rio de Janeiro: FGV, 2013.

VITALE, Denise: Democracia direta e poder local: a experiência brasileira do orçamento participativo. In NOBRE, Marcos \& COELHO, Vera Schattan P. (orgs): Participação e Deliberação - Teoria Democrática e Experiências Institucionais no Brasil Contemporâneo. São Paulo, Editora 34, 2004.

WAMPLER, Brian e AVRITZER, Leonardo: Públicos participativos: sociedade civil e novas instituições no Brasil democrático. In NOBRE, Marcos \& COELHO, Vera Schattan P. (orgs): Participação e Deliberação - Teoria Democrática e Experiências Institucionais no Brasil Contemporâneo. São Paulo, Editora 34, 2004.

ZAVASCKI, Teori Albino: Processo Coletivo, 6a ed. São Paulo: RT, 2013.

ZUFELATO, Camilo: Coisa Julgada Coletiva. São Paulo: Saraiva, 2011. 


\section{ANEXO I}

\section{CARTA CONVITE PARA ENTREVISTA}

Prezado(a) Exmo(a). Sr(a). Dr. Des.

Vimos solicitar a Vossa Excelência a possibilidade de receber o pesquisador Fernando Muniz Shecaira, mestrando vinculado ao Departamento de Direito Processual Civil da Faculdade de Direito da Universidade de São Paulo (FDUSP), para tratar do estudo por ele desenvolvido, acerca da participação em julgamentos de casos repetitivos.

O estudo, orientado pela Ilma. Sra. Profa. Dra. Susana Henriques da Costa, requer o levantamento de dados mediante entrevistas com Magistrados relatores de casos repetitivos do Tribunal de Justiça de São Paulo.

Dessa forma, solicitamos a colaboração de Vossa Excelência, no sentido de participar da entrevista, a ser realizada por data e horário de vossa escolha, tendo-se em vista uma previsão de curta duração das atividades.

Outrossim, asseguramos a confidencialidade, por meio do termo de responsabilidade e sigilo a esta carta anexado, com o compromisso de utilizar os dados obtidos unicamente aos objetivos propostos no estudo.

Além disso, os nomes dos Magistrados, assim como quaisquer sinais ou dados que possam identificá-los, serão omitidos do texto da pesquisa, em respeito aos padrões éticos, sendo certo que os resultados estarão disponíveis para a sua apreciação e consulta.

Aproveitamos o ensejo para renovar os votos da mais elevada estima e máxima consideração.

São Paulo, _ de março de 2019

$\overline{\text { Susana Henriques da Costa }}$ Professora Dra. Orientadora
Fernando Muniz Shecaira

Pesquisador 


\section{ANEXo II}

\section{$\underline{\text { TERMO DE CONSENTIMENTO E SIGILO }}$}

Pesquisador: Fernando Muniz Shecaira, brasileiro, solteiro, pesquisador, portador de cédula de identidade de $\mathrm{n}^{\mathrm{o}} 38.769 .459-4$, inscrito no cadastro de pessoa física sob o $\mathrm{n}^{\mathrm{o}}$ 382.862.428-66, residente e domiciliado na Rua Prof. João Arruda, 168, Ap. 112, São Paulo - SP.

Pesquisa: Participação nos julgamentos de casos repetitivos.

Objeto da pesquisa: A pesquisa, desenvolvida para a elaboração de dissertação de mestrado, cursado na Faculdade de Direito da Universidade de São Paulo, objetiva analisar a participação de litigantes nos julgamentos de casos repetitivos no Tribunal de Justiça do Estado de São Paulo.

Uso da entrevista: o conteúdo da entrevista será utilizado para fins acadêmicos, no âmbito da dissertação de mestrado a ser apresentada na Faculdade de Direito da Universidade de São Paulo. Ressalvadas orientações em contrário, será garantida a confidencialidade da entrevista no texto do trabalho, comprometendo-se, assim, a (i) manter sigilo, tanto escrito como verbal, de todos os dados e informações referentes aos entrevistados; (ii) não revelar, reproduzir, utilizar os dados e informações referentes aos entrevistados, que possibilitem a sua direta identificação; (iii) não revelar dados de eventuais partes citadas durante a realização de entrevistas.

Destaca-se que todos os documentos e dados, inclusive o caderno de anotações de entrevistas e eventual gravação, são de propriedade do pesquisador e serão por ele armazenados, para uso exclusivo na elaboração do estudo ora descrito.

$\mathrm{Eu}$, , estou de acordo com os termos

e com a participação da pesquisa em referência.

São Paulo, de 2018

Entrevistado 
ANexo III

\section{TÓPICO GUIA PARA ENTREVISTAS}

Objeto de pesquisa: Como se dá a participação dos litigantes nos julgamentos de casos repetitivos no TJSP.

Instruções: Os desembargadores serão incentivados a falar sobre 3 (três) tópicos. Dentro desses tópicos, haverá alguns temas que deverão ser abordados. Caso um ou mais dos temas não sejam abordados, o entrevistador deverá sugerir que se fale sobre esses temas. O objetivo é ter uma conversa fluída e que os desembargadores falem sobre os temas. Se eles quiserem falar sobre outros temas, deixar que eles falem.

\section{(1) Necessidade de participação;}

a. IRDR ser processo objetivo (discute-se apenas questões de Direito) e isso implicar a desnecessidade de ouvir a sociedade - iura novit curia.

b. Participação ter capacidade de alterar a opinião dos desembargadores - os votos chegam prontos e são lidos ou há debates prévios (e não registrados) à prolação dos votos.

c. Participação tem capacidade de legitimar a decisão. Participação é mero exercício de contraditório.

d. Representatividade adequada de litigantes habituais frente aos litigantes ocasionais.

(2) Instrumentos de participação; e 
a. Amici curiae - há amigos defendendo interesses de litigantes habituais e litigantes ocasionais.

b. Audiências públicas - forma, local, notícia de realização.

c. Chamamento de instituições - MPE, DPE, PGE?

d. Ofícios e cartas a instituições cadastradas, ou a instituições que já se uma vez participaram.

e. Comunicação online para cadastro de instituições.

f. Apenas entidades ou quaisquer pessoas podem participar?

(3) Resultados da participação.

a. Participação foi capaz de influenciar o resultado do julgamento.

b. Participação causou tumulto processual.

c. Viabilidade de participarem várias entidades / pessoas.

d. Na ausência de participação, quais foram as consequências?

e. Quais podem ser outras vias participativas? 